\title{
Estudos geoelétricos em aterro controlado no município de Caçapava do Sul - RS
}

\author{
Ana Carolina Oliveira dos Santos', Fernanda Vargas de Mello², Juliana de Souza Corrêa Kamphorst ${ }^{3}$, \\ César Augusto Moreira ${ }^{4}$
}

\author{
'Graduação em Geofísica, Universidade Federal do Pampa, Caçapava do Sul \\ ${ }^{4}$ Professor Adjunto, Universidade Federal do Pampa, Caçapava do Sul
}

\section{Resumo}

A aplicação de métodos geofísicos em estudos ambientais, essencialmente na caracterização e monitoramento de áreas contaminadas, é crescente diante da demanda de novas técnicas de investigação ambiental, devido ao risco eminente que a população está sujeita em função da poluição dos solos, águas subterrâneas e possível escassez de água potável. A presença de contaminantes no meio ambiente pode alterar suas propriedades numa gama de variação muitas vezes passível de detecção pela geofísica. Desta forma, este estudo apresenta os resultados da aplicação dos métodos geofísicos de Eletrorresistividade e Potencial Espontâneo, por meio da técnica de Caminhamento Elétrico, em uma área de deposição de resíduos sólidos, com o objetivo de detecção de zonas anômalas aos parâmetros físicos, que podem estar associadas a contaminações provenientes da decomposição de resíduos sólidos. O estudo demonstrou a eficácia dos métodos geofísicos na deteç̧ão de zonas preferenciais de fluxo, sentido de fluxo subterrâneo na área de disposição de resíduos e a ocorrência de intervalos contaminados.

Palavras-chave: Lixo, chorume, potencial de fluxo, aterro sanitário.

\begin{abstract}
The application of geophysical methods in environmental studies, primarily in the characterization and monitoring of contaminated areas, is facing increasing demand for new techniques in environmental research due to the imminent risk that the population is subject depending on the Pollution of soil, groundwater and possible scarcity of drinking water. The presence of contaminants in the environment can change its properties in a range of variation often can be detected by geophysics. Thus, this study presents the results of application of geophysical methods of resistivity and spontaneous potential, using the technique of electrical profiling, in an area of waste disposal, in order to detect anomalous zones to physical parameters that can be associated with contamination from the decomposition of waste. The study demonstrated the effectiveness of geophysical methods to detect zones of preferential flow, direction of groundwater flow in the area of waste disposal and the occurrence of intervals contaminated.
\end{abstract}

Keywords: West, leachate, potential flow, sanitary landfill. 


\section{INTRODUÇÃO}

Atualmente uma das grandes preocupações mundiais é a poluição dos solos e das águas subterrâneas devido ao risco à saúde da população, bem como à escassez da água potável.

O aumento da população mundial é acompanhado pelo crescimento médio da renda familiar, num sistema que estimula o consumo. Neste sentido, nas últimas décadas houve um aumento exponencial na produção de lixo.

No Brasil, a composição do lixo doméstico é de $65 \%$ de matéria orgânica, $25 \%$ de papel, 4\% de metal, $3 \%$ de plástico e 3\% de vidro (Imbelloni, 2007).

O gerenciamento de resíduos sólidos envolve a logística de coleta, transporte, tratamento e disposição em áreas previamente licenciadas e construídas sob critérios técnicos. Este procedimento consome tempo de vultosos recursos.

Desta forma, áreas muitas vezes inapropriadas são utilizadas para destinação final de resíduos. Tais áreas são vulgarmente denominadas "lixão". Em contrapartida, os aterros controlados constituem uma forma organizada de disposição de resíduos, com o objetivo de minimizar os impactos ambientais, embora não necessariamente envolvam a impermeabilização do terreno.

O aterro sanitário é a forma tecnicamente adequada de disposição de resíduos, pois envolve a impermeabilização da base do terreno, construção de sistemas de drenos, condutos e tanque de coleta de chorume, além de sistema de captação de gases e cobertura constante dos resíduos.

Locais de deposição de resíduos sólidos são alvos de muitos estudos ambientais, pois o líquido que percola do lixo, o chorume, pode vir a ser causador de plumas de contaminação no subsolo (Laureano \& Shiraiwa, 2008).

O chorume é originado a partir de processos biológicos, químicos e físicos da decomposição de resíduos orgânicos. O líquido lixiviado é um poluente que contém substâncias tóxicas e perigosas em forma sólida e gasosa, possui coloração escura e odor nauseante. Este líquido pode apresentar elevadas concentrações dos íons cloreto, ferro e zinco. A dissolução do chorume nas águas da chuva e sua percolação no solo, em muitos casos, resultam na contaminação das águas subterrâneas.

Os estudos ambientais em aterros têm grande importância para prevenção de eventuais contaminações, bem como para detecção e monitoramento de áreas contaminadas. Existem duas formas básicas de investigação ambiental: direta ou indireta. A investigação direta está baseada em análise química em amostras de solo e água subterrânea.

Esta forma de investigação possui um ponto negativo, pois apresenta caráter pontual e desconsidera as heterogeneidades intrínsecas ao meio geológico (Moreira \& Braga, 2009). Entretanto, esta é a única forma de quantificação dos compostos químicos que constituem o contaminante.

A investigação indireta pode envolver o uso de sensores remotos e métodos geofísicos. A aplicação dos métodos geofísicos em estudos ambientais, essencialmente na caracterização e monitoramento de áreas contaminadas, é crescente diante da demanda de novas técnicas de investigação ambiental. A possibilidade de aquisição de dados em larga escala a um custo relativamente baixo, além da vantagem de produtos 1D, 2D e 3D, permite uma avaliação adequada do ambiente quando integrado a resultados diretos de investigação (Moreira et al., 2009).

Os métodos geofísicos consistem em medidas de parâmetros físicos característicos dos materiais terrestres. A presença de contaminantes neste ambiente pode alterar suas propriedades numa gama de variação muitas vezes passível de detecção pela geofísica.

Contudo, como forma indireta de investigação, os métodos geofísicos apenas resultam em investigações qualitativas a partir da caracterização de anomalias ao parâmetro físico investigado, sem quantificá-lo.

Segundo CETESB (2001), atualmente os métodos geofísicos têm sido amplamente utilizados neste tipo de estudo devido a sua rapidez e custo relativamente baixo quando comparados a outras técnicas de investigação.

Os principais métodos geofísicos empregados em investigações ambientais são os Elétricos, Eletromagnéticos e Potenciais (CETESB, 2001).

Em estudos no aterro municipal de Cordeirópolis (SP), Moreira et al. (2009) utilizaram medidas de resistividade elétrica, obtidas com a técnica de Caminhamento Elétrico, combinadas com medidas de $\mathrm{pH}$ e Eh em amostras de solo para avaliar o comportamento geoquímico de resíduos sólidos enter- 
rados, durante o processo de degradação de matéria orgânica. Os estudos foram realizados em valas fechadas entre 12/2001 a 12/2007. Os resultados mostraram a presença de valores de resistividade abaixo de $30 \Omega \mathrm{m}$ nas linhas realizadas sobre as valas, sugerindo a presença de chorume. A correlação temporal entre $\mathrm{pH}$ e Eh pode indicar as condições geoquímicas predominantes as quais estão associadas ao padrão de resistividade elétrica. Assim, baixos valores de resistividade associados a baixos valores de $\mathrm{pH}$ e elevados valores de Eh indicam a possível existência de uma pluma de contaminação.

Diferentes métodos geofísicos (Eletrorresistividade, Polarização Induzida e Potencial Espontâneo) foram integrados por Lago et al. (2006) em uma área de disposição de resíduos sólidos urbanos em Bauru - SP, com a finalidade de obter uma caracterização geoambiental adequada. O uso conjunto destes métodos possibilitou resultados significantes. Os baixos valores de resistividade, associados aos baixos valores de cargabilidade em pontos específicos dentro da zona saturada, permitiram identificar anomalias, de modo a caracterizar a presença de contaminação proveniente da disposição de resíduos sólidos. Através da análise dos dados obtidos pelo método de Potencial Espontâneo (SP) foi possível determinar a direção do fluxo da água subterrânea, o qual foi confirmado pelo método de Eletrorresistividade. Com a utilização conjunta desses métodos foi possível, ainda, orientar a locação de ensaios por métodos diretos de investigação, assim como a locação adequada de poços de monitoramento na área.

No trabalho de Gallas et al. (2005) foi utilizado o método de Eletrorresistividade para detectar e mapear uma pluma contaminação causada pelo chorume e oriunda de um aterro sanitário do município de Londrina (PR). O estudo foi satisfatório, pois o método atingiu plenamente o objetivo proposto, além disso, os autores fizeram uma descoberta inesperada, que foi a identificação de outra direção do fluxo de contaminação que flui através de fraturas horizontais ou superfícies de alteração em contato dos derrames basálticos.

\section{METODOLOGIA}

\section{I Área de estudos}

A área de estudos é um aterro municipal controlado, desativado, situado na Vila do Segredo, zona rural do município de Caçapava do Sul, Estado do Rio Grande do Sul. O local está distante cerca de $6 \mathrm{~km}$ a sudoeste do centro da cidade. O acesso até a área é feito através da RS-357, que liga os municípios de Caçapava do Sul e Lavras do Sul (Figura 1).

A Vila do Segredo está situada no Km 4 desta rodovia, a partir da qual é possível acessar a área via estrada secundária. O aterro dista cerca de 1500 metros da Vila do Segredo.

O município possui cerca de 32.574 habitantes (IBGE, 2007) com produção diária atual em torno de 12 toneladas de lixo doméstico.

A área de estudos foi utilizada entre dezembro de 1997 e fevereiro de 2006, como depósito de resíduos sólidos domiciliares oriundos no município de Caçapava do Sul (Figura 2). Nesta época a produção de resíduos domiciliares no município era de aproximadamente 10,2 toneladas/dia.

A área de disposição de resíduos está localizada numa propriedade de 12 hectares, dos quais 5 hectares foram licenciados pela FEPAM (Fundação Estadual de Proteção Ambiental Henrique Luiz Roessler - RS). Entretanto, apenas metade da área licenciada foi utilizada para deposição dos resíduos, segundo determinação do órgão fiscalizador.

A área de disposição de resíduos consiste num sistema de 5 células ou valas, sequencialmente fechadas. Estas células foram impermeabilizadas em suas bases e possuem drenos para o escoamento por gravidade dos líquidos gerados pela decomposição dos resíduos, sentido à lagoa de decantação. $\mathrm{O}$ projeto inicial, não implantado, compreende um sistema de recirculação, ou seja, bombeamento dos efluentes da lagoa e reintrodução na área de resíduos enterrados.

Para monitoramento do impacto ambiental e para controle de contaminantes eram realizadas apenas análises químicas nos principais afluentes e córregos da região.

A finalização das atividades de disposição de resíduos foi sucedida pela cobertura dos resíduos, por uma camada de solo e posterior vegetação.

Apesar de desativado, o aterro ainda recebe resíduos para transbordo em contêineres e transporte para a cava de uma mina de carvão desativada, município de Minas do Leão (RS). 


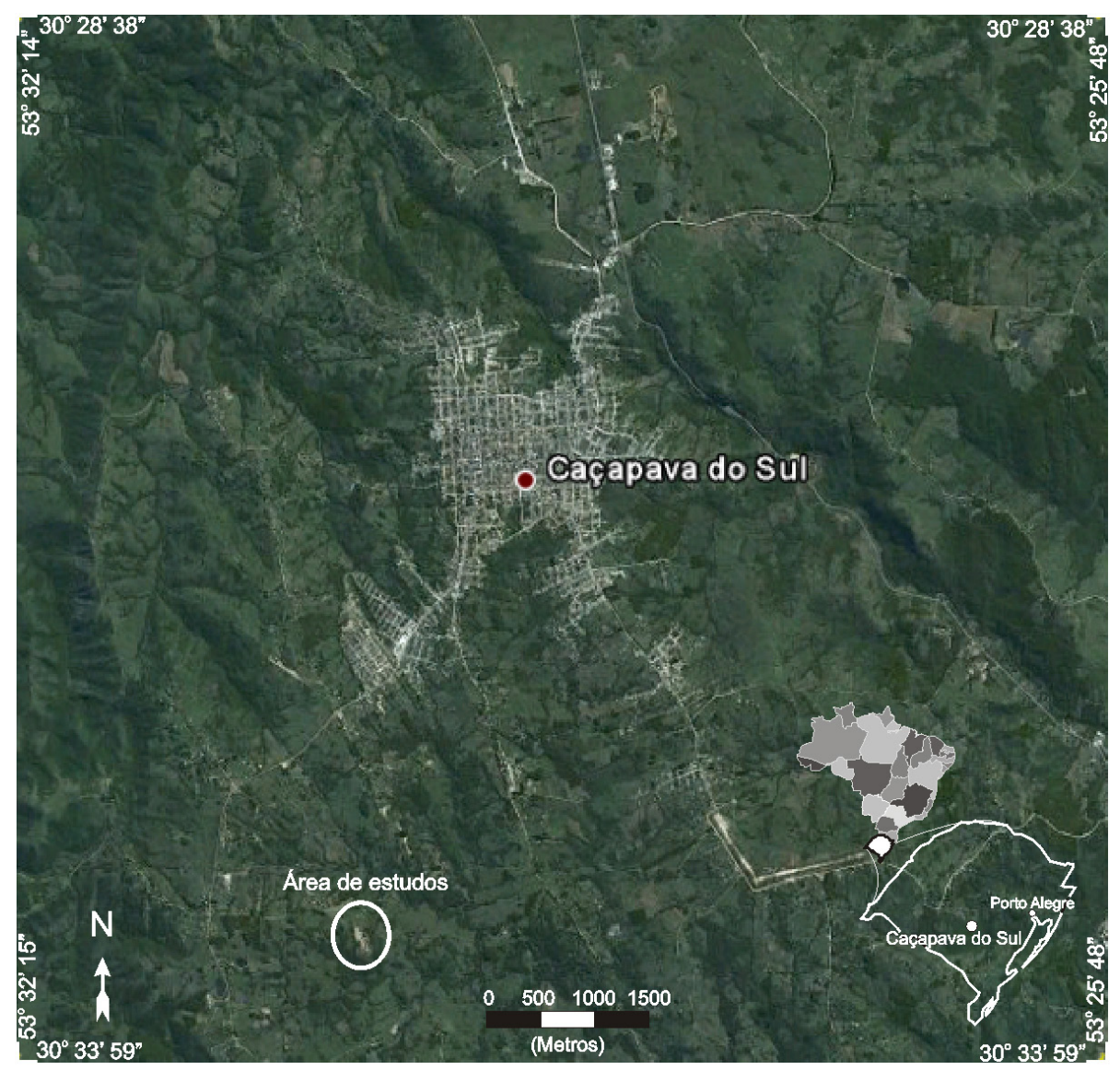

Figura 1. Localização da área de estudos.

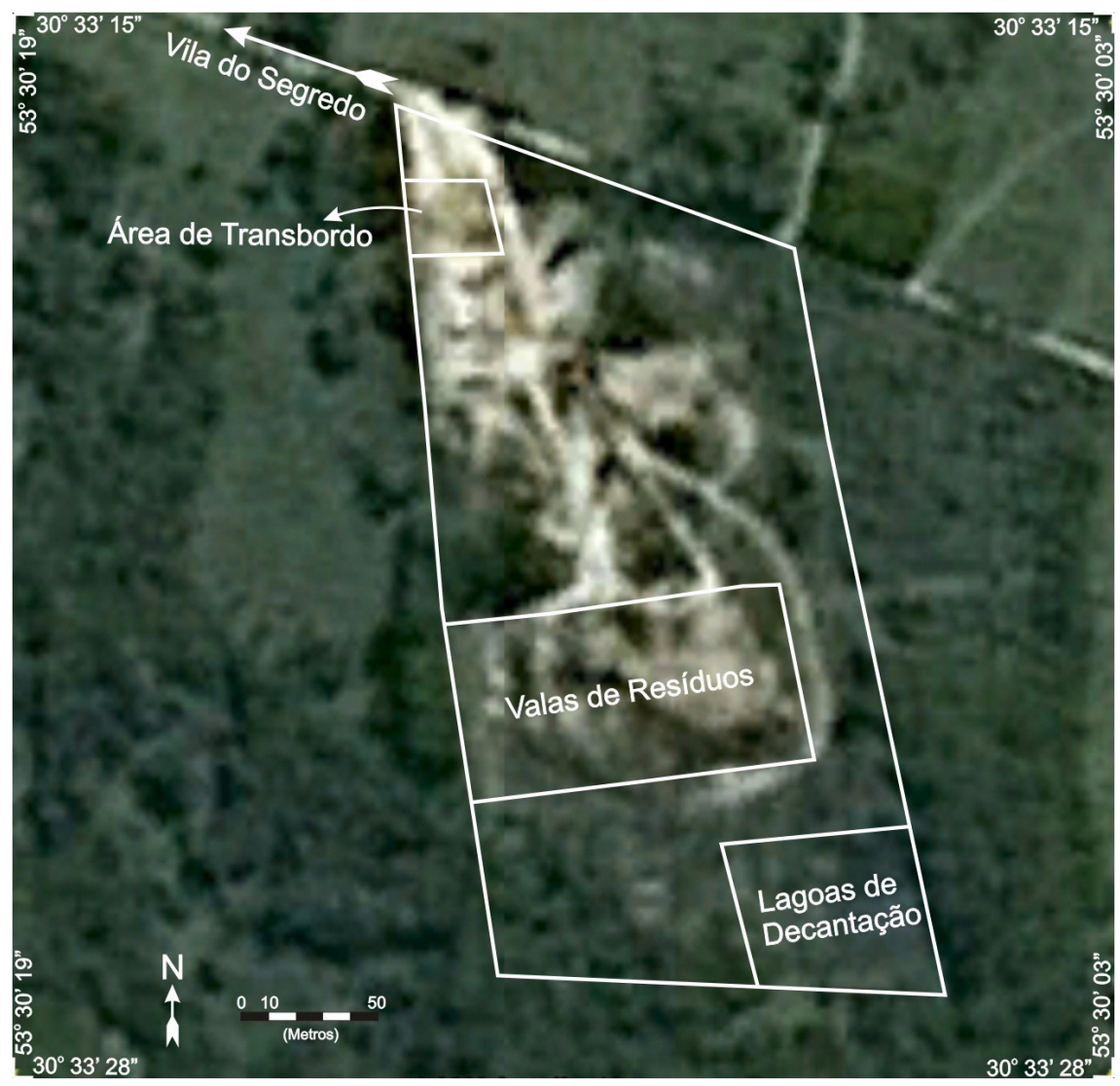

Figura 2. Mapa da área de estudo. 


\section{2 GEOLOGIA}

No contexto geológico local, a área do aterro esta assentada no Granito Caçapava ou Complexo Granítico Caçapava do Sul.

Este complexo compreende dois corpos graníticos intrusivos, dos quais um tem maiores dimensões e empresta a denominação ao complexo. Este corpo principal possui forma aproximadamente dômica ou ovalada, eixo maior orientado na direção norte-sul com cerca de 25 quilômetros de extensão por 10 quilômetros de largura máxima. O corpo com dimensões menores é denominado Granito Santo Ferreira e está localizado a sudeste do corpo principal. O Granito Santo Ferreira foi atribuído a este complexo devido à similaridade composicional e estrutural (Porcher \& Lopes, 2000; Ribeiro et al., 1966).

Este complexo é regionalmente inserido na Bacia do Camaquã e é totalmente envolvido pelas rochas metassedimentares e metavulcânicas da Formação Vacacaí, cujas direções de foliação são geralmente paralelas e sub-paralelas à margem do granito, ou mesmo, concordantes com as estruturas planares do próprio granito (Ribeiro et al., 1966).

A composição mineralógica principal é representada por quartzo, feldspato alcalino e plagioclásio, onde a biotita está presente nas diversas fácies, e a hornblenda é identificada apenas nos tipos tonalíticos. Os minerais acessórios mais comuns estão representados por zircão, alanita, apatita e minerais opacos. São encontrados, ainda, porém com menor frequencia, os minerais: titanita, rutilo e esfênio. Clorita, epidoto, muscovita, sericita, carbonato e minerais opacos secundários constituem a mineralogia resultante das transformações metamórficas associadas à fase de deformação transcorrente (Porcher \& Lopes, 2000).

Segundo Porcher \& Lopes (2000), diversos autores sugeriram que o complexo granítico é formado por intrusões múltiplas de diferentes idades, as quais variam entre $540 \mathrm{Ma}$ e $600 \mathrm{Ma}$. Os autores sugerem, ainda, que as intrusões seriam originadas da refusão de um embasamento siálico Arqueano/ Proterozóico, em que as fácies não foliadas seriam pré-cinemáticas e as foliadas seriam sincinemáticas em relação ao evento de deformação que afetou os xistos encaixantes.

Caçapava do Sul está situada sobre litologias que, em geral, possuem pequena potencialidade hidrogeológica. Está incluída no Sistema de Aquífero Embasamento Cristalino II e no Aquiclude Eo-Paleozóico, logo, faz parte de sistemas incipientemente fraturados ou com predominância de litologias argilosas (Machado \& Freitas, 2005).

A existência de um menor fraturamento, além de diminuir a potencialidade aquífera, revela que estes sistemas possuem baixa vulnerabilidade à contaminação e apenas em alguns locais, por exemplo, mais urbanizados ou de deposição de resíduos sólidos, pode existir algum risco de poluição (Machado \& Freitas, 2005).

\section{MÉTOdOS GEOFísICOS}

\section{I ELETRORRESISTIVIDADE}

O método de Eletrorresistividade é baseado na Lei de Ohm, a qual descreve que a razão entre voltagem e corrente é constante num condutor linear (Equação 1). Consiste na introdução de corrente elétrica no terreno e posterior medição da diferença de potencial por meio de um arranjo composto, geralmente, por quatro eletrodos convencionados em A, B, M e N.

$$
\begin{aligned}
& \mathrm{V}=\mathrm{RI} \\
& \text { (Equação 1) }
\end{aligned}
$$

Os eletrodos A e B são responsáveis pela introdução da corrente, onde o circuito é conectado a um amperímetro por meio de cabos elétricos. Os eletrodos $\mathrm{M}$ e $\mathrm{N}$ são utilizados para medir a diferença de potencial criada pelo circuito de corrente. Esses eletrodos são conectados, também, através de cabos elétricos a um voltímetro capaz de medir a diferença de potencial entre eles. É válido salientar que a abertura dos dipolos $\mathrm{AB}$ (corrente) e $\mathrm{MN}$ (potencial), no momento da medida, definem a profundidade de investigação.

Para Braga (2001), a diferença de potencial em um meio homogêneo difere de um meio heterogêneo, devido a alterações na propagação do campo. Na prática, o subsolo não pode ser considerado 
um meio homogêneo, desta forma, a quantia medida representa uma média de todas as resistividades verdadeiras em um volume de material em subsuperfície. Assim, a variável que expressa o resultado das medições do método de Eletrorresistividade é a resistividade aparente pa.

\subsection{POTENCIAL ESPONTÂNEO (SP)}

É um método caracterizado pela realização de leitura de campo elétrico natural sem necessidade de quaisquer circuitos de injeção de corrente elétrica ou geração de campo eletromagnético.

Segundo Lowrie (2007) e Telford, Geldart e Sheriff (1990), o potencial natural ou espontâneo é causado por ações eletroquímicas ou mecânicas. A água subterrânea é o agente mais importante no mecanismo de geração de potencial devido a variações eletrolíticas. Entretanto, os potenciais podem estar associados à presença de corpos metálicos, contatos entre as rochas de diferentes litologias, atividade bioelétrica de materiais orgânicos, porosidade, migração de fluidos, variação de resistividade, umidade do solo, gradientes térmicos e de pressão nos fluidos de subsuperfície.

O trabalho de Nyquist e Corry (2002) analisa o modelo proposto por Sato e Mooney (1960), e concordam que anomalias detectadas em corpos de sulfeto resultam de processos químicos de oxidação/redução. Porém, propõem que um fio conectado a dois materiais imersos num eletrólito com potencial de oxidação/redução suficientemente distintos para que haja uma reação espontânea, pode medir um valor de potencial elétrico. Os autores sugerem que em estudos de contaminação ambiental, um arranjo dipolar mede meramente a diferença de potencial entre os pares de eletrodos, respectivamente posicionados sobre a anomalia e fora da área de influência, que pode ser representada por uma pluma de contaminação.

\section{TÉCNICA E ARRANJOS DE CAMPO}

A técnica de Caminhamento Elétrico consiste na investigação lateral do parâmetro físico em uma ou mais profundidades, para isto os eletrodos de transmissão e recepção são fixados em superfície e as leituras são processadas com a movimentação dos eletrodos de recepção ao longo da linha de aquisição. Esta técnica permite a aquisição de dados em duas dimensões (2D).

Este trabalho utiliza os arranjos Dipolo-dipolo e Base fixa. O arranjo Dipolo-dipolo é caracterizado pela equidistância entre os eletrodos $A B$ e MN. Durante o desenvolvimento do ensaio, os eletrodos $\mathrm{AB}$ permanecem fixos e $\mathrm{MN}$ são movidos ao longo da linha. O espaçamento entre os dipolos $\mathrm{AB}$ e $\mathrm{MN}$ é crescente, onde cada deslocamento infere um nível maior de investigação, sendo que a profundidade teórica é $\mathrm{R} / 2$, isto é, é a distância média entre o centro de $\mathrm{AB}$ e $\mathrm{MN}$.

$\mathrm{O}$ arranjo de Base Fixa utiliza apenas um par de eletrodos A e M, sendo M fixo na superfície e A movido ao longo do arranjo.

\section{AQUISIÇÃO E PROCESSAMENTO}

O estudo foi realizado entre os meses de dezembro/2009 e março/2010, período historicamente seco. Entretanto, houve períodos de chuva anômalos. Após a reunião dos dados disponíveis, as atividades de campo foram iniciadas com uma visita preliminar a área do aterro.

Foi observado que o local apresenta uma área para transbordo de resíduos em contêineres. $\mathrm{O}$ local das valas de deposição dos resíduos está parcialmente coberto por solo e vegetação, e as lagoas de decantação apresentam transbordo de água/chorume, de modo que esta solução escoa pela superfície.

A etapa de aquisição dos dados iniciou com a aplicação do método de Eletrorresistividade, técnica de Caminhamento Elétrico (CE) em arranjo Dipolo-dipolo, com espaçamento de $10 \mathrm{~m}$ entre eletrodos e leituras de resistividade em 8 níveis de investigação. Foram realizadas 8 linhas, das quais 7 sobre a região das valas de resíduos, e uma externa denominada linha de referência (Figura 3).

Após o método de Eletrorresistividade, foi aplicado o método de Potencial Espontâneo, por meio da técnica de Caminhamento Elétrico em arranjo de Base Fixa, com malha irregular e pontos espaçados a cada 5 metros, num total de 342 pontos (Figura 4). 


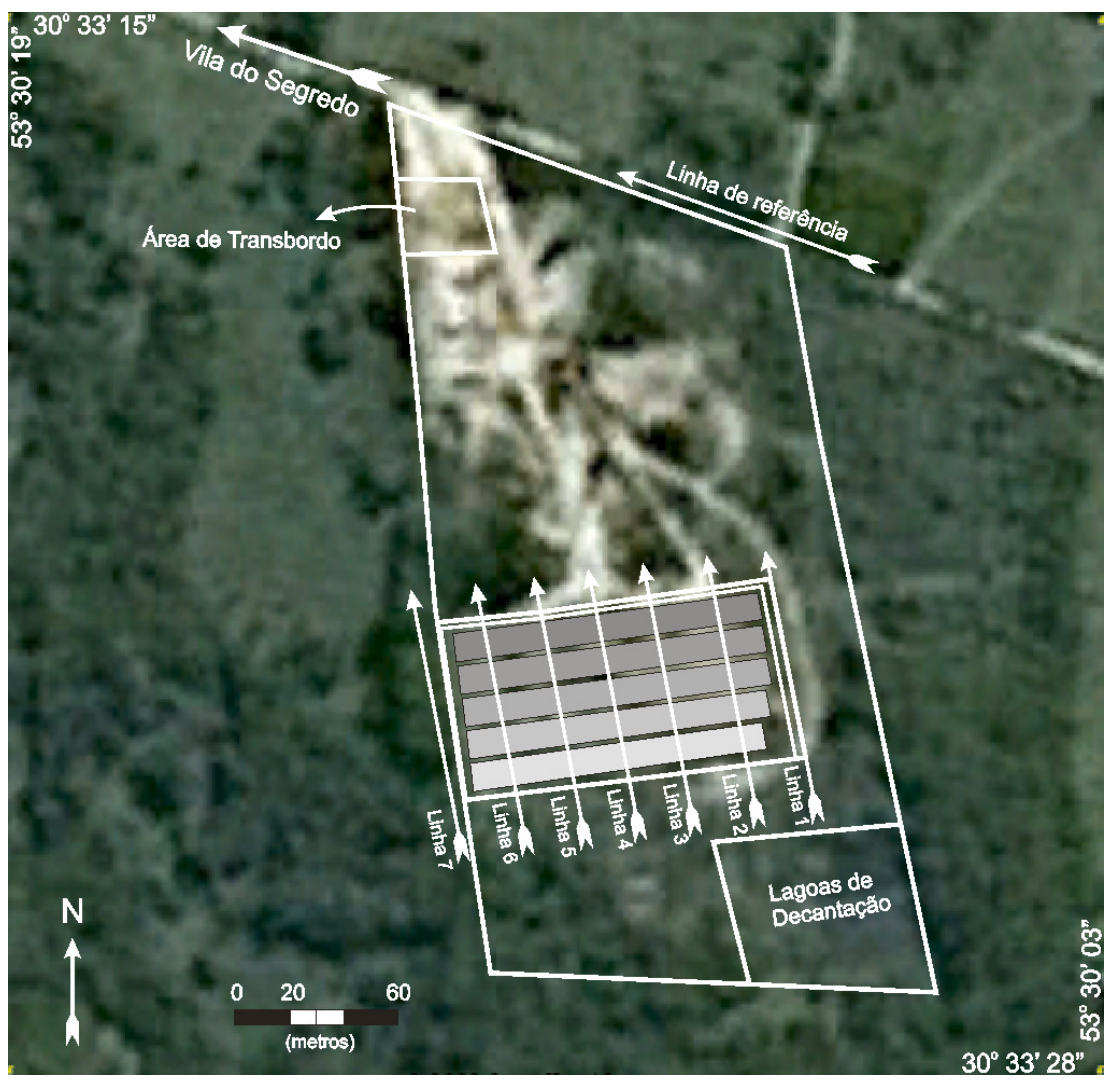

Figura 3. Linhas de Caminhamento Elétrico sobre a região das valas.

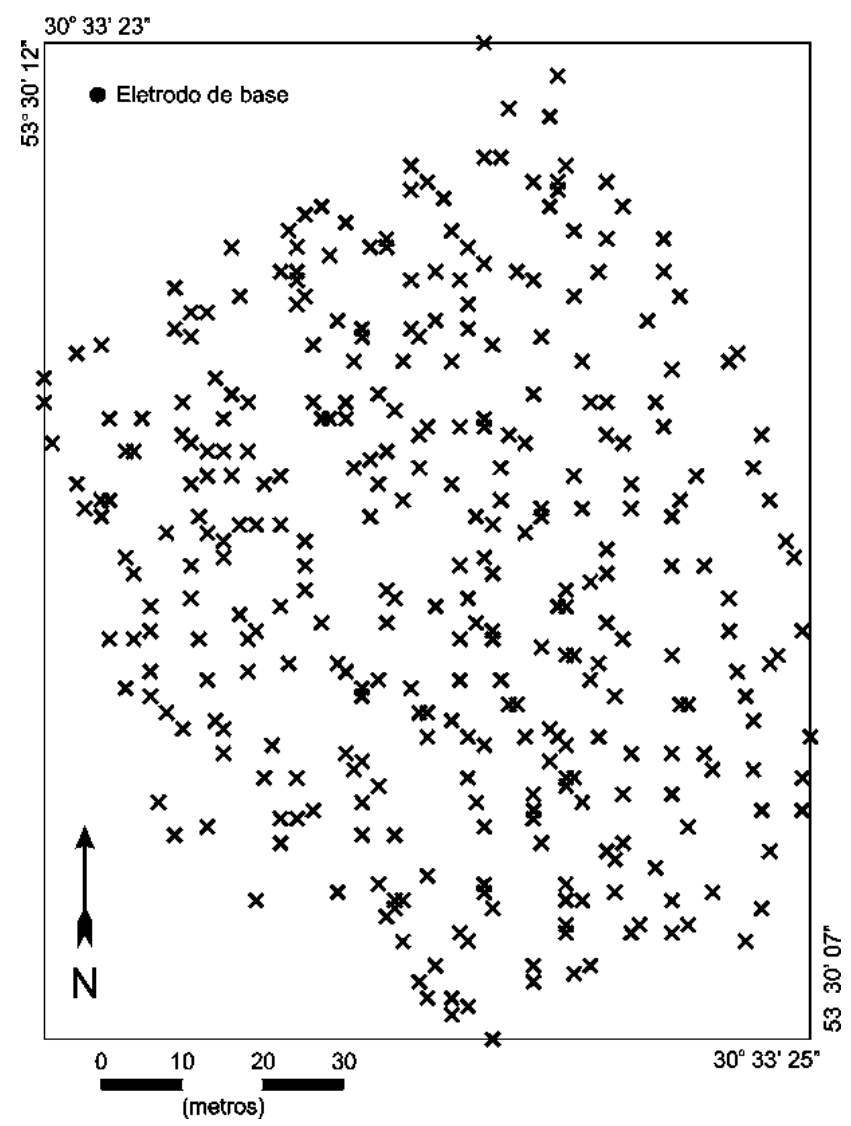

Figura 4. Pontos de leitura de potencial espontâneo. 
A malha consistiu em um eletrodo de medição fixado a montante do fluxo e outro móvel, medindo a diferença de potencial após o fechamento do circuito. O método de Potencial Espontâneo foi realizado com eletrodos não polarizáveis, constituídos por uma solução a base de sulfato de cobre.

Neste trabalho foi utilizado o resistivímetro SYSCAL Pro, fabricado pela Iris Instruments (França), com $250 \mathrm{~W}$ de potência, $2.5 \mathrm{~A}$ de corrente máxima, resolução de até $1 \mu \mathrm{V}$ e 10 canais simultâneos de leitura. O equipamento realiza medidas simultâneas de resistividade e cargabilidade, além de leituras de potencial espontâneo.

Os dados de resistividade elétrica foram tabelados no programa Surfer, versão 8, desenvolvido pela Golden Software (Estados Unidos), e posteriormente processados no programa Res2dinv, versão 3.4, desenvolvido pela Geotomo Software (Malásia).

O Res2dinv é um programa que determina, automaticamente, um modelo de resistividade bidimensional (2D) para subsuperfície a partir de dados obtidos no levantamento de campo (Griffiths \& Barker, 1993). O modelo 2D, usado pelo programa de inversão, consiste de blocos retangulares, os quais são fracamente ligados à distribuição dos dados dos pontos na pseudosseção.

Os dados de potencial elétrico natural foram tabelados e processados no programa Surfer e apresentados sob a forma de mapa de superfícies de isovalores. As medidas em campo foram georreferenciadas por GPS portátil, marca Garmin, modelo E-trex Vista. Os valores de latitude, longitude e cota foram tabelados e processados no programa Surfer e apresentados sob a forma de mapa de altitude geométrica, seguindo os isovalores de cota.

O Surfer é um pacote de programas gráficos comerciais, utilizados para o cálculo e a confecção de mapas de variáveis por meio de métodos de interpolação. Para interpolação dos dados de ambos os mapas, foi adotado o método de vizinhança ou ligação simples (natural neighbor), onde os grupos iniciais são determinados pelos mais altos coeficientes de associação mútua, ou seja, para a admissão de novos membros é suficiente determinar quais os representantes de maior coeficiente de associação com um dos elementos de determinado grupo (Landim, 2004).

\section{RESULTADOS E DISCUSSÃO}

Com base no relevo da região das valas, a espessura máxima estimada para a camada de resíduos é de aproximadamente 15 metros.

Em campo foi possível verificar que a espessura do depósito diminui gradativamente para oeste. Portanto, a camada mais espessa está situada à leste. A linha 1 foi realizada fora do depósito, em sua lateral leste. As linhas 2, 3, 4, 5 e 6 foram realizadas sobre a região das valas. A linha 7 foi realizada na lateral oeste, fora do depósito (Figura 3).

A linha de referência, realizada na estrada de acesso à área, apresentou apenas valores acima de $60 \Omega \mathrm{m}$. Desta forma, os valores inferiores são considerados zonas contaminadas. Com isso, as linhas foram reprocessadas e limitadas a dois intervalos de cores, ou seja, valores acima e abaixo de $60 \Omega$ m (Figuras 5 e 6).

A linha 1 não apresentou valores abaixo de $60 \Omega \mathrm{m}$, portanto não há indícios de contaminação. A linha 2 apresenta uma anomalia de baixa resistividade próximo à superfície, com cerca de 60 metros de extensão e espessura de 2 a 3 metros. Na linha 3 também é possível verificar a existência de uma anomalia de baixa resistividade próxima à superfície, com extensão de 75 metros e espessura de até 5 metros (Figura 5).

A linha 4 mostra uma anomalia de baixa resistividade próxima à superfície com extensão superior a 80 metros, pois observamos que a linha não cobriu toda a extensão da pluma. A zona de contaminação possui espessura inferior a 15 metros, sendo que grande parte da extensão observada apresenta espessura em torno de 1,5 metros (Figura 5).

$\mathrm{Na}$ linha 5 é possível observar uma diminuição na extensão da anomalia de baixa resistividade, medindo cerca de 35 metros (Figura 6). No entanto, parte desta possui espessura de aproximadamente 15 metros em quase toda sua extensão e está mais distante da superfície em relação as linhas 2 , 3, e 4 (Figura 5).

A linha 6 apresenta duas pequenas e distantes zonas anômalas, com valores inferiores a $60 \Omega \mathrm{m}$, as quais não ultrapassam 8 metros de extensão e espessura, além de não apresentarem conexão com a superfície (Figura 6). 

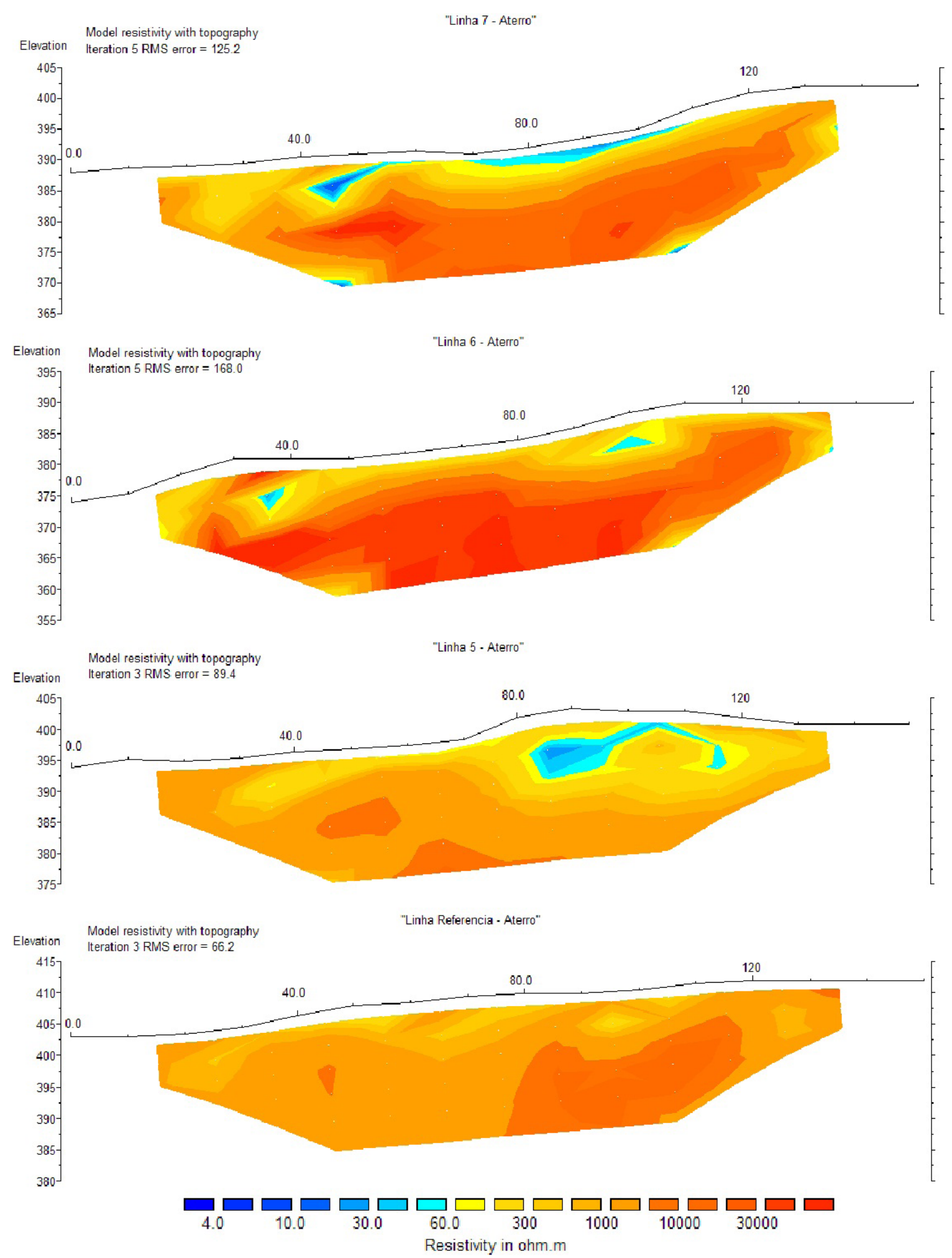

Figura 5. Seções de CE reprocessadas. Linha de referência e linhas 1, 2, 3 e 4.

$\mathrm{Na}$ linha 7 é possível identificar duas anomalias de baixa resistividade muito próximas, sendo que uma é mais distante da superfície e possui extensão próxima a 20 metros e espessura em torno de 15 metros. A outra possui extensão de aproximadamente 40 metros e espessura inferior a 2,5 metros (Figura 6). 

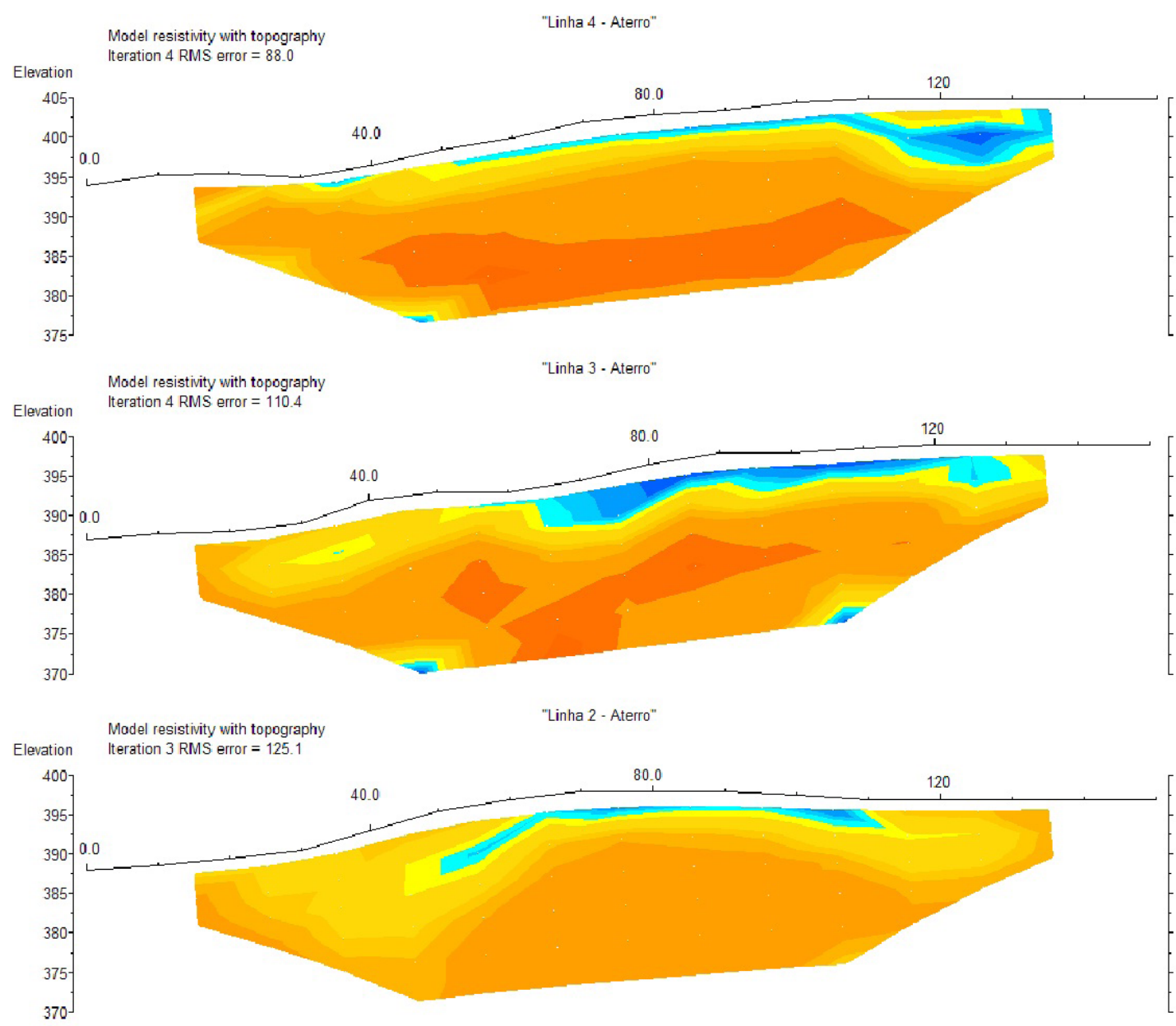

Model resistivity with topagraphy $\quad$ "Linha 1 - Aterro"

Iteration 4 RMS error $=76$
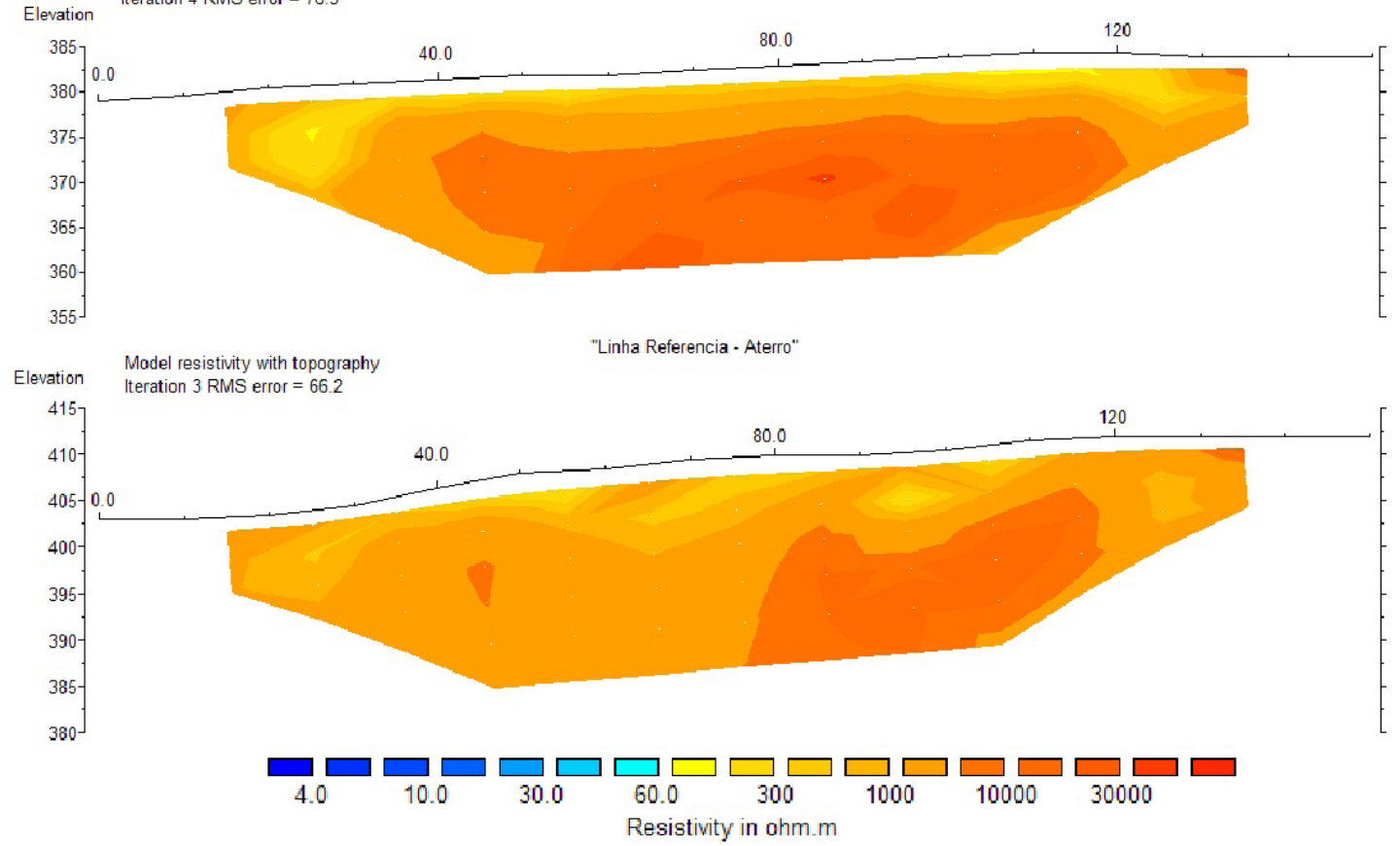

Figura 6. Seções de CE reprocessadas. Linha de referência e linhas 5, 6 e 7.

Os resultados obtidos no método de Eletrorresistividade corroboram com os resultados apre- 
sentados no trabalho de Moreira, Braga e Fries (2009), realizado em um aterro controlado do tipo vala, onde a linha de referência apresentou valores altos de resistividade em relação às linhas realizadas sobre a região das valas de resíduos. Neste estudo as zonas com resistividade abaixo de $30 \Omega \mathrm{m}$ foram consideradas intervalos de acumulação de resíduos. No presente estudo, os valores de resistividade anômalos foram abaixo de $60 \Omega \mathrm{m}$, pois a linha de referência apresentou apenas valores mais elevados de resistividade.

Os dados de relevo são apresentados em mapa (Figura 7). É possível observar que existe uma grande área entre o centro e o norte com relevo mais elevado e plano (cores claras no mapa), a qual possui declividade acentuada a sudeste e suavizada a sudoeste. Na região sul, a declividade é significantemente acentuada.

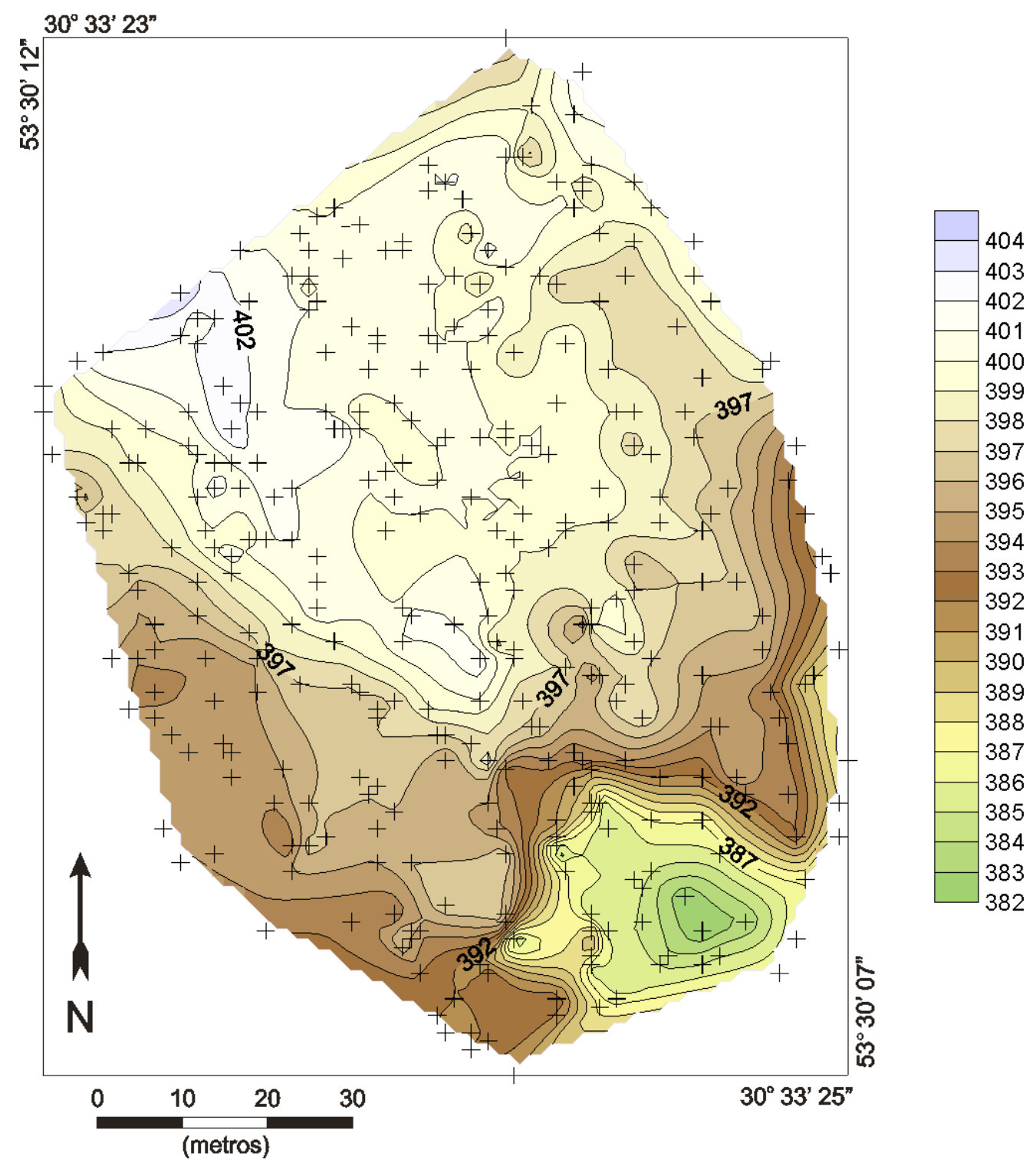

Figura 7. Mapa de altitude geométrica da área de estudo. (Figura 8).

Os dados de potencial elétrico natural são apresentados sob a forma de superfície de isovalores 


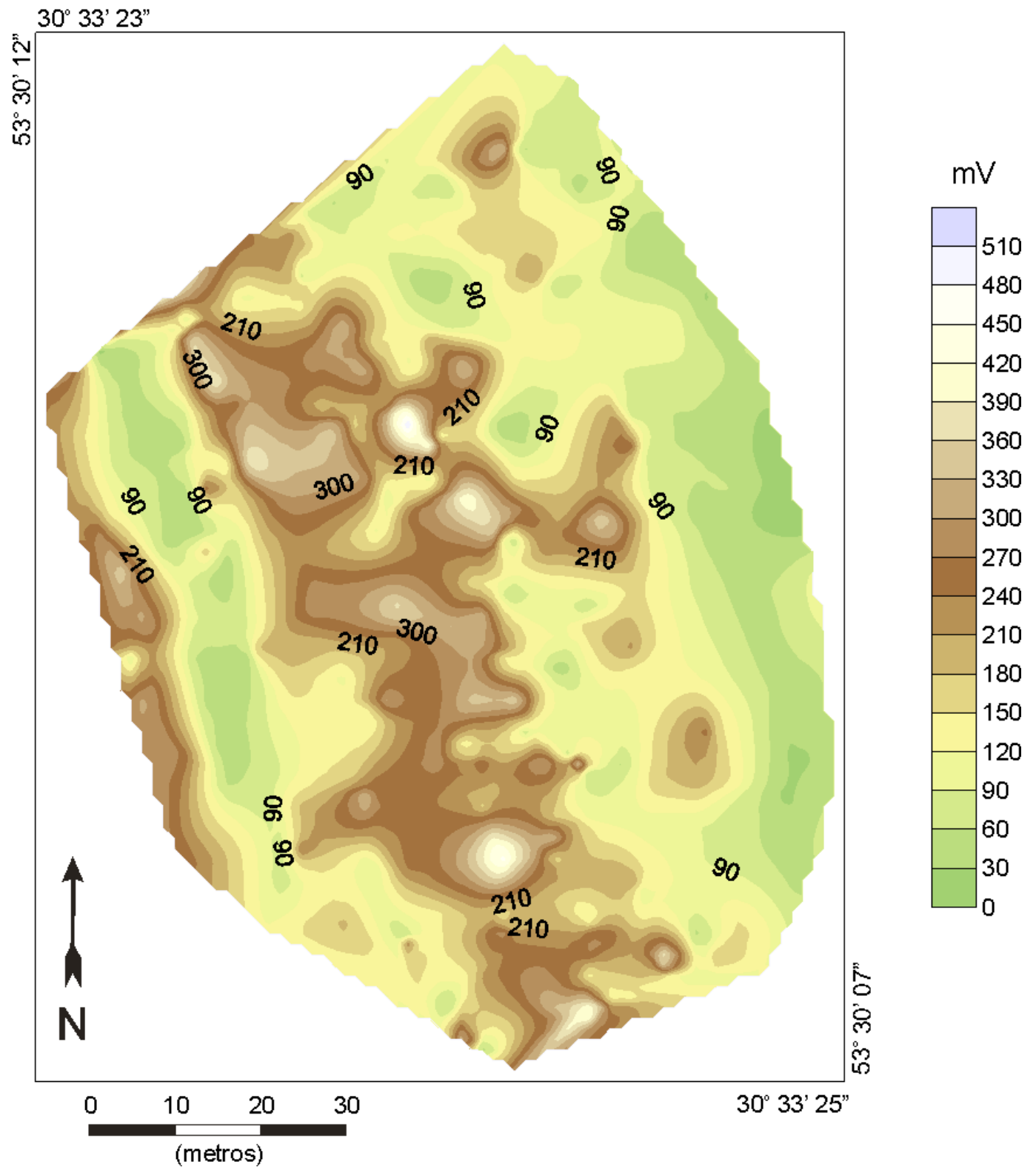

Figura 8. Mapa de Potencial Espontâneo.

Os valores de potencial espontâneo natural variam de $0 \mathrm{mV}$ a $510 \mathrm{mV}$, com predomínio de valores acima de $150 \mathrm{mV}$ na faixa central da área com direção NNW/SSE, onde prevalece relevo plano e mais elevado.

As regiões leste e oeste da área com direção NNW/SSE e valores abaixo de $150 \mathrm{mV}$, coincidem com as áreas de declive. Esta descrição indica a geração de potencial de fluxo originado nas áreas elevadas (elevado potencial elétrico) e fluxo para as áreas topograficamente mais baixas.

A região de declive à SSE e com valores abaixo de $150 \mathrm{mV}$ pode ser explicada pela presença de um dreno (Figura 9). A área destacada no mapa apresenta desnível de norte para sul. Desta forma, o sentido leste/oeste segue os isovalores de relevo.

Contudo, existe lateralmente um grande contraste de valores de potencial elétrico entre a área em destaque no mapa e áreas ao redor. Este contraste pode estar associado à presença de uma provável continuidade do dreno (Figura 9). 


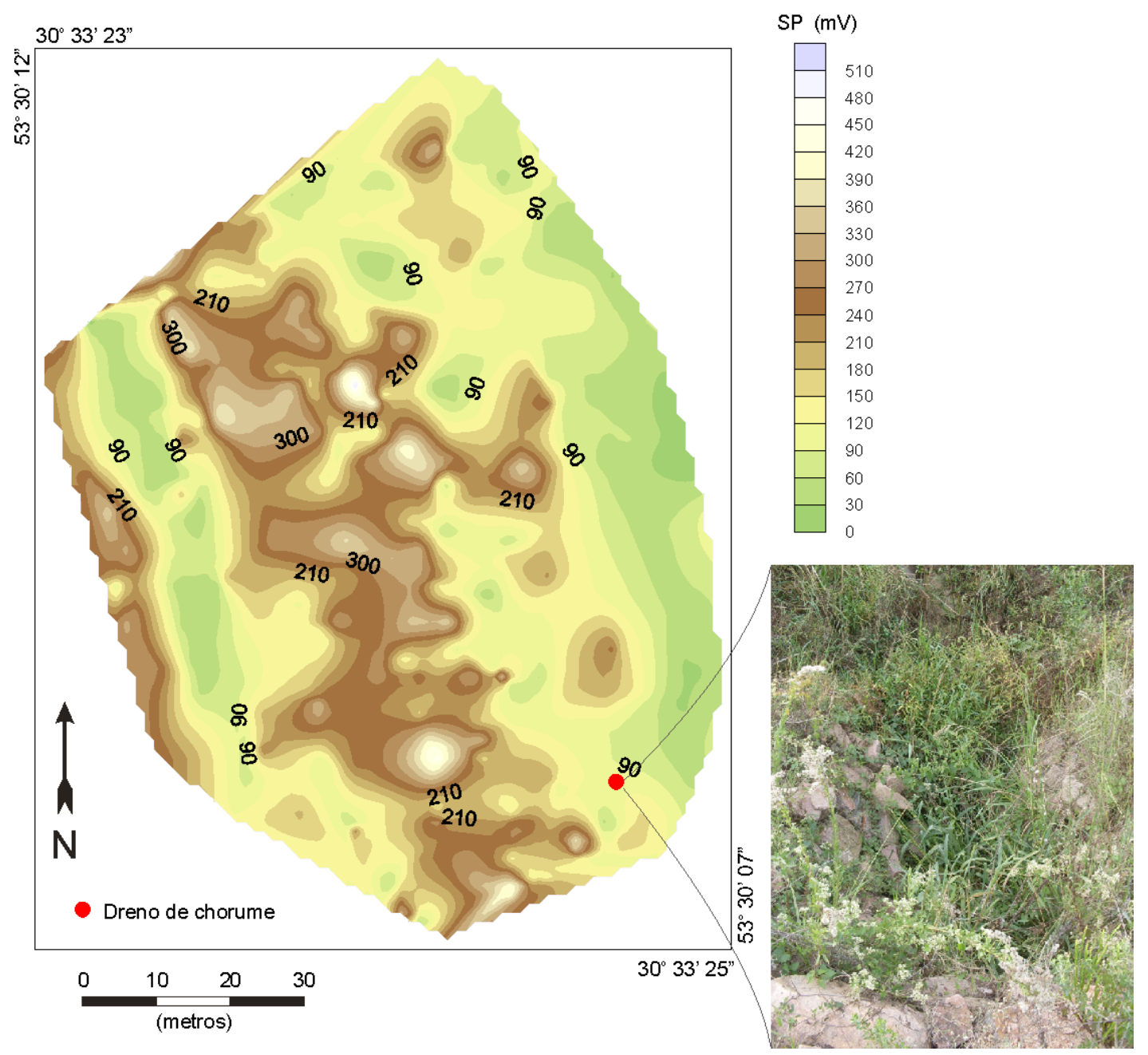

Figura 9. Mapa de Potencial Espontâneo interpretado.

\section{CONCLUSÕES}

A relação direta entre anomalias de baixa resistividade e a presença de líquidos provenientes da degradação de materiais orgânicos demonstra a eficácia do método de Eletrorresistividade. A aplicabilidade deste método em estudos de aterros é comprovada no presente estudo e por diversos trabalhos anteriores.

Os resultados indicam que o chorume está acumulado horizontalmente, a uma profundidade que não ultrapassa 15 metros, isto é, no intervalo da camada de resíduos. Desta forma é possível inferir que as valas não apresentam indícios de perfuração ou rompimento da manta de impermeabilização.

Os altos valores de resistividade presentes nas partes profundas das seções indicam ausência de fraturamento com abertura suficiente para o fluxo de chorume abaixo do intervalo de resíduos.

O cruzamento entre os mapas de altitude geométrica e potencial elétrico natural indica que existe uma relação entre declividade e potencial de fluxo. Os baixos valores de voltagem representam a zona de fluxo, devido à presença de ânions que fluem concomitantemente com o fluxo.

O mapa de potencial espontâneo apresenta uma diferença clara entre valores altos e baixos. Desta forma, as zonas de alto potencial estão à montante do fluxo e as zonas de baixo potencial à jusante.

Desta forma, o método de Potencial Espontâneo foi satisfatório na determinação da direção do fluxo subterrâneo. Há uma relação entre um dreno aflorante na área e baixos valores de potencial elétrico. O prolongamento desta anomalia de forma alongada na área do depósito é um indicativo da continuidade deste dreno na base do aterro. 


\section{REFERÊNCIAS}

BRAGA, A. C. de O.. Métodos Geoelétricos Aplicados. Módulo: Hidrogeologia. Versão 3.0. Rio Claro: Unesp, 2001. Disponível em: www.rc.unesp.br/. Acessado em: 16nov2009.

CETESB - COMPANHIA DE TECNOLOGIA DE SANEAMENTO AMBIENTAL. Manual de gerenciamento de áreas contaminadas / CETESB. Coord. SERPA, E. L.; MARKER, A.. 2. ed.. São Paulo, 2001. $389 \mathrm{p}$.

GALLAS, J. D. F. et al. Contaminação por chorume e sua detecção por resistividade. Revista Brasileira de Geofísica, v. 23, n. 1, p. 51-59, jan./mar. 2005.

GRIFFITHS, D.; BARKER, R.. Two-dimensional resistivity imaging and modelling in areas of complex geology. Journal of Applied Geophysics, v. 29, n. 3, p. 211-226, abr. 1993.

IBGE 2007- Instituto Brasileiro de Geografia e Estatística. Disponível em: www.ibge.gov.br/. Acessado em: 08 dez2009.

IMBELLONI, R.. Lixo no Brasil. 2007. Disponível em: http://www.resol.com.br/. Acessado em: 10dez2009.

LAGO, A. L.; ELIS, V. R.; GIACHETI, H.. Aplicação integrada de métodos geofísicos em uma área de disposição de resíduos sólidos urbanos em Bauru - SP. Revista Brasileira de Geofísica, Rio de Janeiro, v. 24, n.3, p. $357-374$, jul./set. 2006.

LANDIM, P. M. B.. Análise estatística de dados geológicos. 2 ed.. São Paulo: Edunesp, 2004. 253p.

LAUREANO, A. T.; SHIRAIWA, S.. Ensaios Geofísicos no Aterro Sanitário de Cuiabá - MT. Revista Brasileira de Geofísica, Rio de Janeiro, v. 26, n.2, p. 173-180, abr./jun. 2008.

LOWRIE, W.. Fundamentals of Geophysics. Second Edition. New York: Cambridge University Press, 2007. $375 p$.

MACHADO, J. L. F.; FREITAS, M. A.. Mapa hidrogeológico do Rio Grande do Sul: relatório final. Porto Alegre: CPRM, 2005. 71p.

MOREIRA, C. A.; BRAGA, A. C. de O.. Anomalias de Cargabilidade em Aterro de Resíduos Sólidos Domiciliares. Revista Brasileira de Geofísica, Rio de Janeiro, v. 27, n.1, p. 55-62, jan./mar. 2009.

MOREIRA, C. A.; BRAGA, A. C. de O.; FRIES, M.. Degradação de resíduos e alterações na resistividade elétrica, pH e Eh. Revista Brasileira de Geofísica, Rio de Janeiro, v. 27, n.2, p. 283 - 293, abr./jun. 2009.

NYQUIST, Jonathan. E.; CORRY, Charles. E.. Self-potential: The ugly ducking of environmental geophysics. The Leading Edge, v. 1, p. 446-451, 2002.

PORCHER, C. A.; LOPES, R. da C.. Cachoeira do Sul - Folha SH.22-Y-A. Relatório Final, Brasilia: CPRM, 2000. $147 \mathrm{p}$.

RIBEIRO, M. et al. Geologia da Quadrícula de Caçapava do Sul, RS, Brasil. Bol. Depto. Nacional da Produção Mineral. Rio de Janeiro, v. 127, p. 64-69, 1966.

SATO, Motoaki.; MOONEY, Harold. M.. The electrochemical mechanism of sulfide selfpotential. Geophysics, v. 25 , n. 1, p. 226-249, 1960.

TELFORD, W. M.; GELDART, L. P.; SHERIFF, R. E.. Applied Geophysics. 2 ed.. New York: Cambridge University Press, 1990. p. 774. 